\title{
Sexual Conflict, Life Span, and Aging
}

\author{
Margo I. Adler and Russell Bonduriansky \\ Evolution \& Ecology Research Centre and School of Biological, Earth and Environmental Sciences, University \\ of New South Wales, Sydney 2052, New South Wales, Australia \\ Correspondence: margo.adler@gmail.com
}

The potential for sexual conflict to influence the evolution of life span and aging has been recognized for more than a decade, and recent work also suggests that variation in life span and aging can influence sexually antagonistic coevolution. However, empirical exploration of these ideas is only beginning. Here, we provide an overview of the ideas and evidence linking inter- and intralocus sexual conflicts with life span and aging. We aim to clarify the conceptual basis of this research program, examine the current state of knowledge, and suggest key questions for further investigation.

Sexual conflict arises because the sexes maxi$\checkmark$ mize their fitness via different, and often mutually incompatible, strategies, and its signature has been detected across a wide range of morphological, physiological, behavioral, and life-history traits in many species. A number of investigators have suggested that sexual conflict could play an important role in the evolution of two particularly interesting life-history traits: life span and aging (Svensson and Sheldon 1998; Promislow 2003; Bonduriansky et al. 2008; Maklakov and Lummaa 2013). Sexual conflict can affect life span and aging rate at both proximate (within-generation) and ultimate (evolutionary) scales. Sexually antagonistic behavioral or physiological interactions that increase mortality rate in one or both sexes (interlocus sexual conflict) could drive the evolution of faster life histories. Moreover, sex-specific optimization of reproductive strategies may often result in sex differences in life span and aging rates, and sexually antagonistic selection on shared genetic architecture can displace one or both sexes from their sex-specific optima for these traits (intralocus sexual conflict). Conversely, a change in life histories because of environmental fluctuations could affect the degree of sexual conflict in a population and influence sexual coevolution. Although evidence for sexual conflict is rapidly accumulating, our understanding of its relationship to life span and aging remains rudimentary. In this review, we provide a critical review of recent literature and highlight areas that require further investigation.

\section{DOES INTERLOCUS SEXUAL CONFLICT AFFECT THE EXPRESSION AND EVOLUTION OF LONGEVITY AND AGING?}

Proximate Effects of Sexually Antagonistic Interactions on Life Span and Aging

The near-ubiquity among species of sex differences in optimal mating rate has led to numerous examples of adaptations in one sex

Editors: William R. Rice and Sergey Gavrilets

Additional Perspectives on The Genetics and Biology of Sexual Conflict available at www.cshperspectives.org

Copyright (C) 2014 Cold Spring Harbor Laboratory Press; all rights reserved; doi: 10.1101/cshperspect.a017566

Cite this article as Cold Spring Harb Perspect Biol 2014;6:a017566 
(typically males) that function to manipulate individuals of the opposite sex (usually females) into mating at a suboptimal rate (Parker 1979; Arnqvist and Rowe 2005). Such interactions may reduce life span or increase aging rate in one or both sexes and could thus influence the evolution of life histories. Male strategies that function to increase female mating rate or reproductive investment can increase immediate mortality in females through direct injury, resulting in reduced female life span. For example, in natural populations of many species of waterfowl, forced copulation of females by one or more extra-pair males appears to be a common phenomenon. Because females vigorously resist mating with extra-pair males, forced copulation attempts can result in severe injuries, and in extreme cases even death, for the female (Adler 2010). Similarly, in feral sheep, females are exposed to high levels of male harassment and injury during the breeding season, resulting in a female-biased mortality rate (Réale et al. 1996). Male-imposed injuries to females through coercive mating strategies are documented across taxa, sometimes resulting from bizarre adaptations, such as the "hypodermic genitalia" found in the true bug infraorder Cimicomorpha (Heteroptera), in which males inseminate females by stabbing them in the abdomen, often resulting in injury and infection (Stutt and Siva-Jothy 2001; Tatarnic et al. 2014).

Although mating-related injuries to females have generally been regarded as a side effect of male reproductive strategies, some investigators have suggested that such injuries may be adaptive for males. Injured females may be less likely to remate (to avoid further costs), thus reducing the risk of sperm competition for the males (Johnstone and Keller 2000). Injured females may also respond by increasing immediate reproductive output as a form of "terminal investment," an increased reproductive investment in individuals nearing the end of life (as conceived by Williams 1966), resulting in more or higherquality offspring for the male (Michiels 1998). However, this idea remains controversial and requires direct empirical support (Morrow et al. 2003).
In addition to bodily injury, females may also suffer life span-reducing mating costs through exposure to sexually transmitted infections and parasites, as well as mating-related behaviors that reduce the ability to forage or increase vulnerability to predation (e.g., Jennions and Petrie 2000; Arnqvist and Rowe 2005). In water striders, premating struggles drastically increase the likelihood of predation, and females faced with such mortality risk often respond by engaging in "convenience polyandry" (Rowe 1994). In some species, males appear to intimidate females into mating by drumming on the water surface during struggles - a behavior that attracts predators, which are more likely to attack the female than the male (Han and Jablonski 2010).

In some species, sexually antagonistic interactions may result in latent costs that elevate aging rate. Latent costs may result from somatic wear and tear associated with courtship or premating struggles. For example, in the neriid fly Telostylinus angusticollis, both sexes suffered accelerated aging when the operational sex ratio was biased toward the opposite sex (Adler and Bonduriansky 2011). Males may use strategies that elevate female investment in the current reproductive bout. Such a strategy can maximize a male's fitness gain from the mating, but can result in latent costs for females as a result of the trade-off between reproduction and somatic maintenance (sensu Kirkwood 1977). A well-known example of a male adaptation to increase female immediate reproductive investment is the "toxic ejaculate" of male Drosophila, laden with accessory gland proteins (Acp), such as the "sex peptide," that can increase female oviposition rate but reduce life span (Chapman et al. 1995; Wigby and Chapman 2005), although this effect has been shown to vary with female nutritional status (Fricke et al. 2010). Similarly, males may be selected to elevate female resource allocation to offspring via epigenetic modification of genes in the sperm genome that are involved in resource extraction from the mother (Moore and Haig 1991; Haig 2000). Like Acp-mediated effects on female fecundity, such parent-of-origin (genomic imprinting) effects on female resource al- 
location are thought to result in latent costs (i.e., accelerated aging) in females (Haig 2000). Females are expected to retaliate by silencing the corresponding genes in the egg - a parental tugof-war that may account for the evolution of genomic imprinting at some loci (Moore and Haig 1991; Haig 2000).

\section{Environmentally Mediated Changes in the Degree of Sexual Conflict May Affect Life Span and Aging Rate within Populations}

There exist some interesting examples of environmental changes that alter the degree of sexual conflict within populations and thereby also bring about changes in life span and aging in females and/or males. Magurran and Seghers (1994) found that female guppies in high-predation sites reduced defense against unwanted males, whereas males at such sites exhibited more coercive behaviors. Because females in high-predation sites experienced an extremely high frequency of male harassment (approximately one sneaky mating attempt per minute), they tended to mate at higher than optimal rates and potentially experienced increased survival costs as a result. Hall et al. (2009) subjected a species of cricket with nuptial feeding behavior to experimental evolution under diets of varying quality. The investigators found that females from populations that evolved on a poor-quality diet exhibited increased nuptial feeding, which resulted in reduced male life span. Indeed, any ecological change that affects the intensity of sexual conflict could thereby affect life span and aging, at least in the short term.

\section{Evolutionary Consequences of Interlocus Sexual Conflict for Life Span and Aging}

Interlocus sexual conflict can result in a coevolutionary "arms race" between the sexes, in which the evolution of a male manipulative trait is countered by the coevolution of a female resistant trait, which then selects for increased manipulativeness in males, and so on. But investment in manipulative or defensive traits may come at the cost of survival. Promislow (2003) suggested that species experiencing pervasive sexual conflict are likely to have high mortality rates, because of both the harm inflicted on one sex by the other and the costs of developing traits designed to manipulate or resist the other sex. Although the mortality costs of sexually antagonistic interactions occur on a proximate level, standard evolutionary models predict that increased background mortality rate will result in the evolution of faster aging (Medawar 1946; Williams 1957). Moreover, selection may favor increased resource allocation to manipulative or defensive traits at the cost of investment in late-life survival, such that in populations with high rates of sexual conflict, faster life histories (and increased aging rates) may evolve.

It is important to note, however, that sexual conflict, even if it increases female mortality, might not have the effect of selecting for reduced life span or increased aging rate. Chen and Maklakov (2012) recently showed in the nematode Caenorhabditis remanei that high mortality rates resulted in the evolution of reduced life span only when mortality was random. In contrast, condition-dependent mortality resulted in the evolution of increased life span. Condition-dependent mortality may also account for the evolution of extended life spans in guppies from high-predation environments (Reznick et al. 2006). Insofar as sexually antagonistic interactions result in condition-dependent mortality, sexual conflict could result in strong selection on condition and thus drive the evolution of extended life span and reduced aging rate (Bonduriansky et al. 2008; Maklakov and Lummaa 2013). Interestingly, however, male harassment of females can also result in negative condition-dependent mortality, as has been shown for Drosophila melanogaster, in which males selectively harass larger (more fecund) females, perhaps thereby reducing the advantage for females of expressing a high-condition phenotype (Long et al. 2009). The consequences of sexually antagonistic interactions for mortality rate, and the relation between mortality and condition, require further research. 
M.I. Adler and R. Bonduriansky

\section{DOES INTRALOCUS SEXUAL CONFLICT AFFECT THE EVOLUTION OF LONGEVITY AND AGING?}

\section{Sex-Specific Selection Affecting Life Span and Aging}

The distinct reproductive strategies pursued by the sexes may often generate very different patterns of selection on strategies that affect life span and aging. In particular, the sex (typically males) that competes more strongly for access to mates tends to be selected to pursue a "live fast, die young" strategy, sacrificing longevity for reproductive opportunity. This is because the sexes usually encounter different "opportunity landscapes," with the sex that experiences stronger sexual competition typically in a position to gain more fitness through risky or costly strategies with a high potential short-term payoff (Fig. 1). Consider a "typical" mating system involving males that compete for matings and females that compete for resources and invest heavily in offspring. For a female, high fitness can accrue only gradually, through successful accumulation of resources and production of young (Vinogradov 1998). Although female reproduction is resource-limited and females compete for resources, the fitness payoff from a highquality resource patch is moderated by the amount of time required to exploit the resource and the many additional steps involved in the reproductive process. It rarely makes adaptive sense for a female to risk death or substantial somatic damage or to make a large resource investment, for a chance to acquire a food morsel or nesting site. In contrast, for a male, a single successful mating with a high-quality female can represent a considerable fitness gain. Thus, we suggest that males may often be selected to take greater risks than females or to invest a

\section{A}
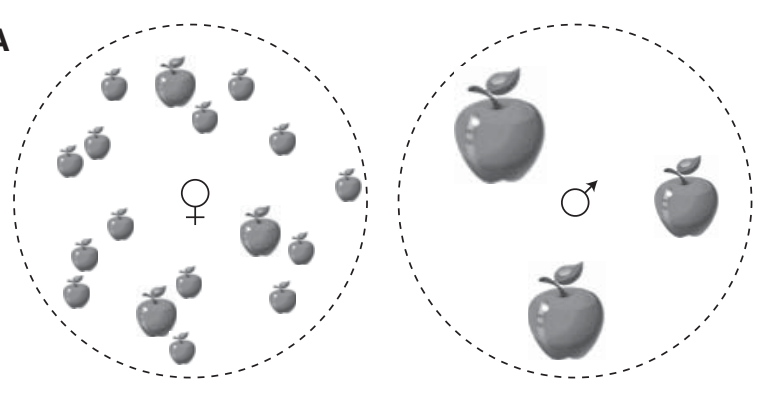

B

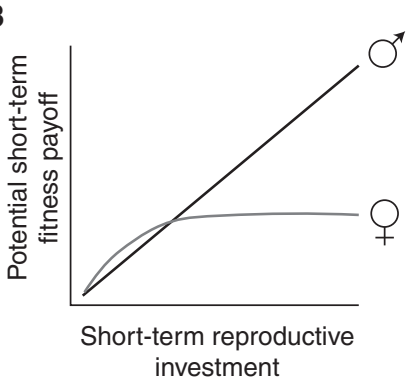

Figure 1. In a "typical" mating system involving stronger sexual competition among males and greater investment in offspring among females, the sexes tend to encounter different "opportunity landscapes" that generate sex-specific selection on longevity and aging rate. $(A)$ Females can gain fitness only in relatively small increments (small apples), by accumulating resources and converting those resources into offspring. In contrast, males have greater opportunity for large, short-term fitness gain (large apples) through mating. ( $B$ ) Thus, for males, large, short-term investments in reproduction (including strategies that involve high risk of injury or death) may be favored by selection because such investments may result in large fitness payoffs. In contrast, females cannot gain equally large short-term fitness payoffs and may therefore be selected to pursue relatively safe, long-term strategies involving greater risk avoidance and larger investment in somatic maintenance. 
larger quantity of limiting resources for the sake of a reproductive opportunity, thereby sacrificing longevity for reproductive opportunity. This is because the potential short-term fitness payoffs available to males tend to be relatively large, such that males have a higher maximum potential reproductive rate than females (Vinogradov 1998).

The sex-specific optima for reproductive investment and life-history scheduling can be manifested in sexual dimorphism for a wide range of behavioral, physiological, and even morphological traits. For example, it is well established in many species that males are prone to engage in risky behavior, such as intrasexual combat over resources or sexual activity in the presence of predators (Andersson 1994; Magurran and Seghers 1994; Candolin 1998). Sex-differences in behavior are mediated hormonally in vertebrates (Adkins-Regan 2005; Juntti et al. 2010; but see Golinski et al. 2011), and there is evidence of a link between testosterone titer and risk-taking behavior (Sapienza et al. 2009; Stanton et al. 2011). Although the relationship between testosterone and sexual behavior appears to be complex (Marler and Moore 1988; Foerster and Kempenaers 2005; McGlothlin et al. 2008), there is evidence of sexually antagonistic selection on testosterone titer (Mills et al. 2012). In addition to stimulating risk-taking behaviors, testosterone also suppresses the immune system (Duffy et al. 2000; Schroderus et al. 2010). As a result of such phenotypic differences, females of many (but not all) species outlive males on average (Comfort 1979; Finch 1990), although sex differences in aging rate are less clear (Bonduriansky et al. 2008).

\section{The Potential for Intralocus Sexual Conflict over Longevity and Aging}

Like most other traits, the behavioral and physiological differences that contribute to differential survival and aging rate in the sexes are likely to share a common developmental-genetic architecture and can therefore be subject to intralocus sexual conflict. Because much of the genome is shared between sexes, sex-specific selection tends to favor different alleles at the same genetic loci in males and females, or to favor the same alleles to a different degree. Selection on one sex can thus displace the other sex from its sex-specific phenotypic optimum. Although selection will favor modifications that weaken genetic constraints on independent evolution of the sexes for such traits, a considerable body of evidence suggests that substantial sexually antagonistic fitness variation segregates in natural and captive populations (Bonduriansky and Chenoweth 2009; Cox and Calsbeek 2009; van Doorn 2009; Connalon et al. 2010).

Establishing intralocus sexual conflict in relation to longevity and aging requires two pieces of information. First, it is necessary to show that selection on these traits is sex-specific. Intralocus sexual conflict becomes increasingly likely with increasing divergence between male and female fitness surfaces, and the most intense conflict occurs when selection is sexually antagonistic (i.e., acts with different sign on sexually homologous traits in males and females). Second, it is necessary to show that genetic constraints impede independent evolution of the sexes. The potential for intralocus sexual conflict increases as the magnitude of the intersexual genetic correlation $\left(r_{\mathrm{mf}}\right)$ increases (Lande 1980; Bonduriansky and Chenoweth 2009). However, a more complete picture of intersexual genetic constraints requires the estimation of the between-sex genetic covariance matrix (B), which incorporates constraints arising from genetic covariances between multiple traits (Lande 1980; Lewis et al. 2011; Gosden et al. 2012). Because fitness and its life-history components are especially prone to environmental effects and genotype $\times$ environment interactions (Roff 1992; Stearns 1992), the most meaningful estimates of selection, as well as intersexual genetic constraints, will come from populations experiencing natural or seminatural environmental conditions.

Evidence of Intralocus Sexual Conflict over Longevity and Aging

Although the extent and intensity of intralocus sexual conflict in relation to longevity and aging rate remain poorly known, some intriguing 
M.I. Adler and R. Bonduriansky

evidence has come from studies documenting sexual dimorphism in longevity and/or aging, quantitative-genetic studies (sometimes combined with assays of sex-specific selection), and artificial evolution studies.

\section{Evidence of Sexual Dimorphism in Longevity and Aging}

The existence of sexual dimorphism in longevity and/or aging rate suggests that intralocus sexual conflict may have occurred during the evolution of these traits. However, in the absence of data on intersexual genetic constraints and sex-specific selection, such evidence is not sufficient to establish that intralocus sexual conflict is currently operating.

A few studies have compared longevity and aging in the sexes in natural or seminatural populations. In a natural population of black field crickets (Teleogryllus commodus), males experienced a higher mortality rate throughout the life span than females, but there was no evidence of faster aging in males (Zajitschek et al. 2009b). However, in a study on the same species in seminatural enclosures, females exhibited a later-starting but more rapid pattern of actuarial senescence (an increase in mortality rate with age) than males (Zajitschek et al. 2009a). In a natural population of the neriid fly Telostylinus angusticollis, extrinsic mortality rate was higher in females than in males, but actuarial aging was detected only in males (Kawasaki et al. 2008). In a wild population of red deer (Cervus elaphus), males experienced earlier and more rapid reproductive aging than females, although different components of performance declined at different rates in each sex (Nussey et al. 2009). In a natural population of blue-footed boobies (Sula nebouxii), the sexes exhibited similar patterns of reproductive senescence (Kim et al. 2011). In free-ranging populations of 24 species of large mammals (Bovidae and Cervidae), males experienced a higher mortality rate and more rapid actuarial senescence than females on average (Lemaitre and Gaillard 2013). A number of studies have also compared longevity and aging in the sexes in the laboratory (e.g., Kawasaki et al. 2008; Rodríguez-Graña et al. 2010; Cebal- los and Kiørboe 2011; Archer et al. 2012b). However, data on laboratory populations must be interpreted with caution, given that relative mortality and aging rates of males and females may be environment-specific.

Some tentative, correlational evidence is also starting to emerge for modern human populations (reviewed in Maklakov and Lummaa 2013). Although women tend to outlive men in most contemporary human populations, sex differences in aging are much less clear, with some somatic indices of senescence showing more rapid deterioration with age in women. There is also evidence, from 18thto 19th-century Finland, suggesting that the number of grandchildren produced increases with survival to old age for women but not for men (Lahdenpera et al. 2007, 2011). However, in recent human populations, such patterns are likely to be shaped by cultural and socioeconomic factors.

\section{Evidence from Quantitative Genetic and Selection Analyses}

A quantitative-genetic analysis of black field cricket (Teleogryllus commodus) life history provided no evidence of intralocus sexual conflict over longevity, because it was found that $r_{\mathrm{mf}}$ for this trait was not significantly different from zero (Zajitschek et al. 2007). Similarly, a very weak $r_{\mathrm{mf}}$ for longevity was observed in the dung fly Sepsis cynipsea (Mühlhäuser and Blanckenhorn 2004). A moderately strong and significant $r_{\mathrm{mf}}$ for longevity (although not aging rate) was observed in D. melanogaster (Lehtovaara et al. 2013). In contrast, in the cricket Gryllodes sigillatus, strong, positive $r_{\mathrm{mf}}$ was observed for both longevity and aging rate (Archer et al. 2012b). This study shows the potential for intralocus sexual conflict in G. sigillatus, but does not show that the sexes are actually displaced from their sex-specific phenotypic optima for these traits. Evidence suggesting intralocus sexual conflict over longevity also comes from a study on the moth Plodia interpunctella (Lewis et al. 2011). Selection was found to favor longer life span (with diminishing returns) in males, but shorter life span in females. Although $r_{\mathrm{mf}}$ for 
longevity was low, it was shown that multivariate genetic constraints, reflected in the malefemale genetic covariance matrix (B), would tend to greatly weaken the potential for each sex (but especially females) to evolve toward its sex-specific longevity optimum. Substantial sexual dimorphism was observed for longevity and other life-history traits, but it remains unclear how far each sex is displaced from its sexspecific phenotypic optimum by intralocus sexual conflict.

\section{Evidence from Artificial Selection Studies}

More compelling evidence of intralocus sexual conflict over longevity was furnished by Berg and Maklakov's (2012) experiment on Callosobruchus maculatus beetles. In this study, artificial selection on males was applied over five generations. Selection on male longevity resulted in a response in females as well, demonstrating a positive intersexual genetic correlation $\left(r_{\mathrm{mf}}>0\right)$ for longevity. Moreover, artificial selection on longevity had opposite effects on fitness in the sexes: In lines selected for longer life span, male fitness was (nonsignificantly) reduced, whereas female fitness was increased. These results suggest that, in the base C. maculatus population from which the experimental lines were derived, the sexes are displaced from their sex-specific longevity optima by sex-specific selection acting on a shared genetic architecture for longevity.

\section{Where Is Intralocus Sexual Conflict Most Likely to Occur?}

Intralocus sexual conflict in relation to longevity and aging rate can be predicted to occur in systems characterized by intense sexual selection on one sex. In such systems, the sexes are likely to exhibit highly divergent reproductive strategies and highly sex-specific patterns of selection on longevity and aging (Promislow 2003). More precisely, the potential for intralocus sexual conflict in relation to longevity and aging rate should relate to differences between the sexes in the maximum potential rate of reproduction (Vinogradov 1998). Although short-term reproductive payoff opportunities may be considerably greater for males in "typical" mating systems (Fig. 1), the "opportunity landscape" experienced by the sexes is likely to depend on mating system parameters, such as the degree of skew in the male mating success distribution, as well as ecological parameters, such as the spatial/temporal distribution and fitness value of food or nest-site resources for females. If matings are relatively easy to achieve, and an additional mating represents only a small fitness gain for a male, then males are unlikely to benefit from taking high risks for mating opportunities, unless they can assess female mate quality and identify particularly high-value mates. Conversely, if food or nest-site resources are sparse, females may be selected to compete and take risks to secure access to them (CluttonBrock 2007, 2009). Likewise, reversed sex roles may select for reversed patterns of selection on longevity and aging (Maklakov and Lummaa 2013).

\section{DOES VARIATION IN LIFE SPAN AND AGING AFFECT SEXUAL CONFLICT?}

Above, we considered the potential for variation in the intensity of sexually antagonistic interactions (interlocus sexual conflict) or sex-specific selection on the life history (intralocus sexual conflict) to affect the expression and evolution of life span and aging. In the following section, we consider the converse possibility: the potential for variation in life span and aging rate to influence the intensity of sexual conflict.

\section{Aging Can Generate Sexual Conflict}

In age-structured populations, in which generations overlap, there is potential for conflict to occur over the age of mating partners. As fertility tends to increase early in life and then decline at older ages for most organisms, mating with a very young or very old individual has the potential to reduce fitness for the other mating partner. This can be true for both sexes, for numerous reasons, including reduced ability to provision or care for young and reduced fertility because of reproductive immaturity, low 
gamete number, or quality (Reinhardt 2007). In the case of very young mating partners, a number of studies have showed that the ability to mate successfully is no guarantee of full reproductive maturity. For example, in the male hide beetle Dermestes maculatus (Jones et al. 2007) and both sexes of the common lizard Lacerta vivipara (Richard et al. 2005), young individuals produce fewer and less viable offspring. Old mating partners, on the other hand, are less likely to be virgin, and thus perhaps more likely to be gamete-depleted or to carry sexually transmitted diseases. Moreover, mutations may accumulate with age in germ cells, reducing the viability, size, or other fitness-related traits of offspring (Johnson and Gemmell 2012). For example, in humans, advanced maternal age reduces offspring viability and survival and greatly increases risk of Down syndrome (reviewed in Gaulden 1992; Bewley et al. 2005), whereas advanced paternal age increases incidence of childhood cancers and neuropsychiatric conditions such as schizophrenia and, fascinatingly, is associated with reduced cognitive abilities (reviewed in Cannon 2009).

Across species, avoiding mating with suboptimal partners is likely to be more important for females, because females typically invest more in offspring and thus have more to lose by poor mate choice. Because surviving to old age might indicate high genetic quality, although somatic condition invariably declines in old age, there is considerable debate about whether females stand to lose or gain, on the whole, by mating with old males (reviewed in Johnson and Gemmell 2012). However, if old males represent suboptimal mating partners, females are expected to evolve preferences that reduce the likelihood of mating with them. Insofar as females can exert such preferences, there is no inherent conflict. However, sexual conflict may occur if males are able to deceive females about their age or if females are unable to choose. Female preferences for "honest" condition-dependent (i.e., costly) signals may be one mechanism by which females can discriminate against old males. For example, Velando et al. (2008) proposed that females may be able to avoid males with oxidatively damaged germline DNA by basing pref- erence on oxidative-dependent sexual signals that decline with age and oxidative damage, such as foot color intensity in the blue-footed booby (Torres and Velando 2007). However, as Kokko (1997) points out, other costly sexual signals may be fixed or may increase with the age of the male, potentially causing sexual signals to become dishonest and resulting in sexual conflict. For example, Dean et al. (2010) showed that male mating rate declines sharply with age in feral fowl (Gallus gallus domesticus), but male dominance rank only declines with age in malebiased sex-ratio groups. Thus, females in a nonmale-biased sex ratio group have the potential to suffer fitness costs from mating with lowfertility dominant males.

If selection tends to favor female avoidance of old males, this is likely to select in turn for increased male persistence or coercion with age. Old males may also elevate their mating effort because the opportunity costs of investing in current mating attempts should tend to decrease as a male ages and his chances of future mating decrease. In other words, selection may favor increased persistence as a form of "terminal investment." An example of this sort of exacerbated sexual conflict comes from the beetle Tenebrio molitor, in which females that mate with old males have smaller, lower-quality offspring (Carazo et al. 2011). As a result, females resist mating with old males and reduce guarding of spermatophores from old males, whereas old males increase guarding of their own spermatophores postcopulation (Carazo et al. 2011).

Males might also face costs by mating with old females, particularly in species in which males invest heavily in each mating. For example, in male copepods, mating entails high costs, and males are consequently limited in the number of females they can mate with during their short life span. Female fertility decreases with age, such that males waste reproductive investment by mating with subfertile females. Ceballos and Kiørboe (2011) suggest this scenario leads males to invest heavily in mate searching and to be particularly choosy. Even in systems in which males invest less per mating, there is potential for males to suffer fitness costs by mating 
with old females. Fricke et al. (2013) show that the increased egg-laying response of females to the male sex peptide is reduced in old females. As male ejaculate products have been shown to be costly for males to produce (Blay and Yuval 1997; Baker et al. 2003; Fricke et al. 2008), mating with old females is likely to result in lost fitness for males.

\section{Variation in Life Expectancy Can Modulate Sexual Conflict}

As noted above, males in polyandrous populations are selected to manipulate the reproductive effort of their mates via accessory-gland products that induce elevated fecundity (Chapman et al. 1995; Wigby and Chapman 2005) or epigenetic parent-of-origin effects that result in increased extraction of maternal resources by offspring (Moore and Haig 1991; Haig 2000). Such male strategies can confer benefits for males by increasing the number or quality of offspring produced from the mating, but females may suffer reduced fitness from overallocating resources to a single reproductive bout. These costs are likely to be latent-that is, manifested later in life as accelerated aging - because latent costs will have little or no effect on the fitness of the male that induces them. Thus, all else equal, the magnitude of such costs to females will depend on female longevity.

Interestingly, this suggests that female longevity may also determine the intensity of sexual conflict in such systems. Using a simple model, Bonduriansky (2014) showed that a change in background mortality rate (resulting, e.g., from increased predation pressure) can result in a short-term relaxation of sexual conflict: If female life expectancy is reduced, then maleinduced elevation in female reproductive effort may become less harmful for females. Similar reasoning suggests that sexual conflict intensity within populations may depend on female condition: If female mortality risk is condition-dependent, then high-condition females (whose life expectancy is high) may experience more intense sexual conflict than low-condition females (whose life expectancy is low). This logic can be extended to female age as well: The re- duced opportunity costs of increased investment in current reproduction late in life might also reduce the intensity of sexual conflict experienced by old females. Indeed, there are a number of reports of increased reproductive investment in old females. For example, brushtail possum females increase investment in lactation and offspring production later in life (Isaac and Johnson 2005), whereas old collared flycatcher females feed fledglings more and lose more weight, at the cost of survival to subsequent breeding seasons (Pärt et al. 1992). The hypothesized link between female life expectancy and sexual conflict intensity awaits empirical verification.

\section{DIRECTIONS FOR FUTURE RESEARCH}

Research on the link between sexual conflict, life span, and aging is still in its early stages, and much work remains to be done. Below, we highlight some gaps in our current understanding and suggest potentially fruitful avenues for future investigation.

Although potential links between sexual conflict, life span, and aging were first identified many years ago, and a number of investigators have discussed this topic (e.g., Svensson and Sheldon 1998; Promislow 2003; Bonduriansky et al. 2008; Maklakov and Lummaa 2013), there is a pressing need to explore these links more formally through analytical and simulation modeling. For example, it would be interesting to explore the consequences of the elevated mortality or accelerated aging that can result from sexually antagonistic interactions for the evolution of male and female life histories. It would also be interesting to model the effects of environmentally induced variation in aging rate on sexual antagonism. Likewise, although theory suggests that variation in extrinsic mortality rate can modulate the intensity of sexual conflict (Bonduriansky 2014), it would be interesting to examine the consequences of long-term changes in mortality rate for sexual coevolution.

Many questions also remain for empirical investigation. With regard to intralocus sexual conflict, comparative, experimental, and geno- 
M.I. Adler and R. Bonduriansky

mic studies are needed to establish when sexspecific selective pressures are most likely to generate strongly divergent selection on life span and aging in the sexes, and to what extent and by what means such conflicts are resolved. We also need a more complete picture of the phenotypic traits that mediate such conflict. Studies examining the ecological, behavioral, or physiological consequences of sex-specific reproductive strategies may illuminate this problem (Magurran and Seghers 1994; Long and Rice 2007; Archer et al. 2012a). The intensity and resolution of such conflicts are likely to be influenced by mating system parameters (Bonduriansky and Chenoweth 2009), but the relationship between mating system and selection on life span and aging may be complex. For example, in some species characterized by intense male-male competition, male fitness may depend largely on the ability to grow to a large body size, and males may therefore be selected for high investment in survival until the critical body size is attained (Graves 2007). Other factors, such as sexual conflict over diet choice (Maklakov et al. 2008; Adler et al. 2013; Reddiex et al. 2013) or the matrilineal inheritance of mitochondria, which limits the scope for evolutionary optimization of mitochondrial function in males (Dowling et al. 2008; Innocenti et al. 2011; Camus et al. 2013), may also influence the dynamics of such conflicts. With regard to interlocus sexual conflict, recent evidence shows that costs to females of male manipulative strategies are likely to be highly context-dependent (Fricke et al. 2009a,b, 2013; Edward et al. 2010). More research is thus needed to establish when and how male strategies impose harm, and how these strategies affect female fitness. To discern general patterns, we need studies under more realistic environmental conditions (see below), as well as on a wide variety of organisms.

A further problem, relating to all of the topics discussed in this paper, is that most of the available empirical evidence relates to life span (which is often used as a proxy for aging rate), although very little is known about the role of aging per se. As a general rule, longevity and aging rate may be expected to covary negatively among taxa because greater risk taking (e.g., by males in "typical" systems) may result in both elevated immediate mortality risk that reduces life expectancy and in greater somatic wear and tear that results in faster aging. Moreover, classic theory suggests that shorter life expectancy will lead to the evolution of faster aging (Williams 1957; Hamilton 1966). However, predictions in relation to aging are complicated by several factors. First, much somatic damage can, in principle, be repaired, so a high rate of wear and tear may be balanced by a large investment in somatic repair. Second, longevity and aging rate may be nonindependent. For example, an organism that survives to an advanced age as a result of low mortality risk in early and middle age may eventually suffer very rapid somatic deterioration (Zajitschek et al. 2009a). Third, when extrinsic mortality is nonrandom with respect to condition, elevated mortality can select for a more robust phenotype that ages less rapidly (Chen and Maklakov 2012), and, in principle, males may therefore evolve to age less rapidly despite having a shorter life expectancy than females (Maklakov and Lummaa 2013). Finally, the quantification of aging rate is a nontrivial problem because aging trajectories are often complex and nonlinear, and different components of performance may decline with age at different rates (Nussey et al. 2009). To understand the relationship between aging and sexual conflict, we need to know which features of the aging trajectory experience the strongest and most divergent patterns of selection in the sexes, and which are subject to the strongest intersexual genetic constraints.

Finally, empirical evidence on the relationship between sexual conflict, life span, and aging comes largely from laboratory studies. Although such studies allow for controlled experimentation, captive conditions may also affect (and often exacerbate) both inter- and intralocus sexual conflicts (Bonduriansky and Chenoweth 2009; Bonduriansky 2014). For example, if life span is extended in the laboratory relative to the wild source population (Kawasaki et al. 2008), then latent fitness costs of male manipulation may be more important for captive females than for their wild counterparts. Captive animals may also tend to experience higher 
population density than is typically the case for natural populations, and captive females may have little opportunity to escape from harassing males, potentially exacerbating the fitness effects of sexually antagonistic interactions. Likewise, because captivity tends to eliminate many sources of viability selection (most of which are shared by the sexes), while typically preserving sex-specific selection pressures associated with sexual competition, captive populations may experience more intense intralocus sexual conflict than wild populations. Even if model organisms such as Callosobruchus maculatus are well adapted to laboratory conditions, an environment in which predators and parasites are rare and resources are superabundant is probably not representative of the conditions experienced by most natural populations. To achieve a better understanding of the relationship between sexual conflict, life span, and aging, it will be necessary to carry out field studies, as well as laboratory studies that subject experimental animals to the kinds of challenges that are faced by natural populations.

\section{ACKNOWLEDGMENTS}

This work is supported by the Australian Research Council through a fellowship and research grant to R.B. We are grateful to Urban Friberg and an anonymous reviewer for helpful comments on a draft of this article.

\section{REFERENCES}

Adkins-Regan E. 2005. Hormones and animal social behavior. Princeton University Press, Princeton, NJ.

Adler M. 2010. Sexual conflict in waterfowl: Why do females resist extra-pair copulations? Behav Ecol 21: 182-192.

Adler MI, Bonduriansky R. 2011. The dissimilar costs of love and war: Age-specific mortality as a function of the operational sex ratio. J Evol Biol 24: 1169-1177.

Adler MI, Cassidy EJ, Fricke C, Bonduriansky R. 2013. The lifespan-reproduction trade-off under dietary restriction is sex-specific and context-dependent. Exp Gerontol 48: 539-548.

Andersson M. 1994. Sexual selection. Princeton University Press, Princeton, NJ.

Archer CR, Sakaluk SK, Selman C, Royle NJ, Hunt J. 2012a. Oxidative stress and the evolution of sex differences in life span and ageing in the decorated cricket, Gryllodes sigillatus. Evolution 67: 620-634.
Archer CR, Zajitschek F, Sakaluk SK, Royle NJ, Hunt J 2012b. Sexual selection affects the evolution of lifespan and ageing in the decorated cricket Gryllodes sigillatus. Evolution 66: 3088-3100.

Arnqvist G, Rowe L. 2005. Sexual conflict. Princeton University Press, Princeton, NJ.

Baker RH, Denniff M, Futerman P, Fowler K, Pomiankowski A, Chapman T. 2003. Accessory gland size influences time to sexual maturity and mating frequency in the stalk-eyed fly, Cyrtodiopsis dalmanni. Behav Ecol 14: 607-611.

Berg EC, Maklakov A. 2012. Sexes suffer from suboptimal lifespan because of genetic conflict in a seed beetle. Proc Biol Sci 279: 4296-4302.

Bewley S, Davies M, Braude P. 2005. Which career first? The most secure age for childbearing remains 20-35. BMJ 331: 588-589.

Blay S, Yuval B. 1997. Nutritional correlates of reproductive success of male Mediterranean fruit flies (Diptera: Tephritidae). Anim Behav 54: 59-66.

Bonduriansky R. 2014. The ecology of sexual conflict: Background mortality can modulate the effects of male manipulation on female fitness. Evolution 68: 595-604.

Bonduriansky R, Chenoweth SF. 2009. Intralocus sexual conflict. Trends Ecol Evol 24: 280-288.

Bonduriansky R, Maklakov A, Zajitschek F, Brooks R. 2008. Sexual selection, sexual conflict and the evolution of ageing and lifespan. Funct Ecol 22: 443-453.

Camus MF, Clancy DJ, Dowling DK. 2013. Mitochondria, maternal inheritance, and male ageing. Curr Biol 22: 1717-1721.

Candolin U. 1998. Reproduction under predation risk and the trade-off between current and future reproduction in the threespine stickleback. Proc Biol Sci 265: $1171-1175$.

Cannon M. 2009. Contrasting effects of maternal and paternal age on offspring intelligence. PLoS Med 6: e1000042.

Carazo P, Molina-Vila P, Font E. 2011. Male reproductive senescence as a potential source of sexual conflict in a beetle. Behav Ecol 22.

Ceballos S, Kiørboe T. 2011. Senescence and sexual selection in a pelagic copepod. PLoS ONE 6: e18870.

Chapman T, Liddle LF, Kalb JM, Wolfner MF, Partridge L. 1995. Cost of mating in Drosophila melanogaster females is mediated by male accessory gland products. Nature 373: $241-244$.

Chen HY, Maklakov AA. 2012. Longer life span evolves under high rates of condition-dependent mortality. Curr Biol 22: 2140-2143.

Clutton-Brock T. 2007. Sexual selection in males and females. Science 318: 1882-1885.

Clutton-Brock T. 2009. Sexual selection in females. Anim Behav 77: 3-11.

Comfort A. 1979. The biology of senescence. Elsevier, New York.

Connalon T, Cox RM, Calsbeek R. 2010. Fitness consequences of sex-specific selection. Evolution 64: 16711682. 
M.I. Adler and R. Bonduriansky

Cox RM, Calsbeek R. 2009. Sexually antagonistic selection, sexual dimorphism, and the resolution of intralocus sexual conflict. Am Nat 173: 176-187.

Dean R, Cornwallis CK, Løvlie H, Worley K, Richardson DS, Pizarri T. 2010. Male reproductive senescence causes potential for sexual conflict over mating. Curr Biol 20: 1192-1196.

Dowling DK, Friberg U, Lindell J. 2008. Evolutionary implications of non-neutral mitochondrial genetic variation. Trends Ecol Evol 23: 546-554.

Duffy DL, Bentley GE, Drazen DL, Ball GF. 2000. Effects of testosterone on cell-mediated and humoral immunity in non-breeding adult European starlings. Behav Ecol 11: 654-662.

Edward DA, Fricke C, Gerrard DT, Chapman T. 2010. Quantifying the life-history responses to increased male exposure in female Drosophila melanogaster. Evolution 65: $564-573$.

Finch CE. 1990. Longevity, senescence, and the genome. University of Chicago Press, Chicago.

Foerster K, Kempenaers B. 2005. Effects of testosterone on male-male competition and male-female interactions in blue tits. Behav Ecol Sociobiol 57: 215-223.

Fricke C, Bretman A, Chapman T. 2008. Adult male nutrition and reproductive success in Drosophila melanogaster. Evolution 62: 3170-3177.

Fricke C, Perry J, Chapman T, Rowe L. 2009a. The conditional economics of sexual conflict. Biol Lett 5: 671-674.

Fricke C, Wigby S, Hobbs R, Chapman T. 2009b. The benefits of male ejaculate sex peptide transfer in Drosophila melanogaster. J Evol Biol 22: 275-286.

Fricke C, Bretman A, Chapman T. 2010. Female nutritional status determines the magnitude and sign of responses to a male ejaculate signal in Drosophila melanogaster. J Evol Biol 23: 157-165.

Fricke C, Green D, Mills WE, Chapman T. 2013. Age-dependent female responses to a male ejaculate signal alter demographic opportunities for selection. Proc Biol Sci 280: 20130428.

Gaulden ME. 1992. Maternal age effect: The enigma of Down syndrome and other trisomic conditions. Mutat Res 296: 69-88.

Golinski A, John-Adler H, Kratochvil L. 2011. Male sexual behavior does not require elevated testosterone in a lizard (Coleonyx elegans, Eublepharidae). Horm Behav 59: 144150.

Gosden TP, Shastri KL, Innocenti P, Chenoweth SF. 2012. The B-matrix harbors significant and sex-specific constraints on the evolution of multicharacter sexual dimorphism. Evolution 66: 2106-2116.

Graves BM. 2007. Sexual selection effects on the evolution of senescence. Evol Ecol 21: 663-668.

Haig D. 2000. The kinship theory of genomic imprinting. Anпu Rev Ecol Syst 31: 9-32.

Hall MD, Bussiere LF, Brooks R. 2009. Diet-dependent female evolution influences male lifespan in a nuptial feeding insect. J Evol Biol 22: 873-881.

Hamilton WD. 1966. The moulding of senescence by natural selection. J Theor Biol 12: 12-45.
Han CS, Jablonski PG. 2010. Male water striders attract predators to intimidate females into copulation. Nat Commun 1: 1-6.

Innocenti P, Morrow EH, Dowling DK. 2011. Experimental evidence supports a sex-specific selective sieve in mitochondrial genome evolution. Science 332: 845-848.

Isaac JL, Johnson CN. 2005. Terminal reproductive effort in a marsupial. Biol Lett 1: 271-275.

Jennions MD, Petrie M. 2000. Why do females mate multiply? A review of the genetic benefits. Biol Rev Camb Philos Soc 75: 21-64.

Johnson SL, Gemmell NJ. 2012. Are old males still good males and can females tell the difference? Bioessays 34: 609-619.

Johnstone RA, Keller L. 2000. How males can gain by harming their mates: Sexual conflict, seminal toxins, and the cost of mating. Am Nat 156: 368-377.

Jones TM, Featherson R, Paris DBBP, Elgar MA. 2007. Agerelated sperm transfer and sperm competitive ability in the male hide beetle. Behav Ecol 18: 251-258.

Juntti SA, Tollkuhn J, Wu MV, Fraser EJ, Soderborg T, Tan S, Honda SI, Harada N, Shah NM. 2010. The androgen receptor governs the execution, but not programming, of male sexual and territorial behaviors. Neuron $\mathbf{6 6}$ : $260-272$.

Kawasaki N, Brassil CE, Brooks R, Bonduriansky R. 2008. Environmental effects on the expression of lifespan and aging: An extreme contrast between wild and captive cohorts of Telostylinus angusticollis (Diptera: Neriidae). Am Nat 172: 346-357.

Kim SY, Velando A, Torres R, Drummond H. 2011. Effects of recruiting age on senescence, lifespan and lifetime reproductive success in a long-lived seabird. Oecologia 166: 615-626.

Kirkwood TBL. 1977. Evolution of ageing. Nature 270: 301304.

Kokko H. 1997. Evolutionarily stable strategies of age-dependent sexual advertisement. Behav Ecol Sociobiol 41: 99-107.

Lahdenpera M, Russell AF, Lummaa V. 2007. Selection for long lifespan in men: Benefits of grandfathering? Proc Biol Sci 274: 2437-2444.

Lahdenpera M, Lummaa V, Russell AF. 2011. Selection on male longevity in a monogamous human population: Late-life survival brings no additional grandchildren. $J$ Evol Biol 24: 1053-1063.

Lande R. 1980. Sexual dimorphism, sexual selection, and adaptation in polygenic characters. Evolution 34: $292-$ 305.

Lehtovaara A, Schielzeth H, Flis I, Friberg U. 2013. Heritability of life span is largely sex limited in Drosophila. Am Nat 182: 653-665.

Lemaitre JF, Gaillard JM. 2013. Male survival patterns do not depend on male allocation to sexual competition in large herbivores. Behav Ecol 24: 421-428.

Lewis Z, Wedell N, Hunt J. 2011. Evidence for strong intralocus sexual conflict in the Indian meal moth, Plodia interpunctella. Evolution 65: 2085-2097.

Long TAF, Rice WR. 2007. Adult locomotory activity mediates intralocus sexual conflict in a laboratory-adapted 
population of Drosophila melanogaster. Proc Biol Sci 274 3105-3112.

Long TAF, Pischedda A, Stewart AD, Rice WR. 2009. A cost of sexual attractiveness to high-fitness females. PLoS Biol 7: e10000254.

Magurran AE, Seghers BH. 1994. Sexual conflict as a consequence of ecology: Evidence from guppy, Poecilia reticulata, populations in Trinidad. Proc Biol Sci 255: 31-36.

Maklakov A, Lummaa V. 2013. Evolution of sex differences in lifespan and aging: Causes and constraints. Bioessays 35: 717-724.

Maklakov AA, Simpson SJ, Zajitschek F, Hall MD, Dessmann J, Clissold F, Raubenheimer D, Bonduriansky R, Brooks RC. 2008. Sex-specific fitness effects of nutrient intake on reproduction and lifespan. Curr Biol 18: 10621066.

Marler CA, Moore MC. 1988. Evolutionary costs of aggression revealed by testosterone manipulations in free-living male lizards. Behav Ecol Sociobiol 23: 21-26.

McGlothlin JW, Jawor JM, Greives TJ, Phillips JL, Ketterson ED. 2008. Hormones and honest signals: Males with larger ornaments elevate testosterone more when challenged. J Evol Biol 21: 39-48.

Medawar PB. 1946. Old age and natural death. Mod Q 2: 3049.

Michiels NK. 1998. Mating conflicts and sperm competition in simultaneous hermaphrodites. In Sperm competition and sexual selection (ed. Birkhead TR, Møller AP), pp. 219-254. Academic, London.

Mills SC, Koskela E, Mappes T. 2012. Intralocus sexual conflict for fitness: Sexually antagonistic alleles for testosterone. Proc Biol Sci 279: 1889-1895.

Moore T, Haig D. 1991. Genomic imprinting in mammalian development: A parental tug-of-war. Trends Genet 7: 4549 .

Morrow EH, Arnqvist G, Pitnick S. 2003. Adaptation versus pleiotropy: Why do males harm their mates? Behav Ecol 14: $802-806$.

Mühlhäuser C, Blanckenhorn WU. 2004. The quantitative genetics of sexual selection in the dung fly Sepsis cynipsea. Behaviour 141: 327-341.

Nussey DH, Kruuk LEB, Morris A, Clements MN, Pemberton JM, Clutton-Brock TH. 2009. Inter- and intrasexual variation in aging patterns across reproductive traits in a wild red deer population. Am Nat 174: 342-357.

Parker GA. 1979. Sexual selection and sexual conflict. In Sexual selection and reproductive competition in insects (ed. Blum MS, Blum NA), pp. 123-166. Academic, New York.

Pärt T, Gustafsson L, Moreno J. 1992. "Terminal investment" and a sexual conflict in the collared flycatcher (Ficedula albicollis). Am Nat 140: 868-882.

Promislow D. 2003. Mate choice, sexual conflict, and evolution of senescence. Behav Genet 33: 191-201.

Réale D, Boussès P, Chapuis JL. 1996. Female-biased mortality induced by male sexual harassment in a feral sheep population. Can J Zool 74: 1812-1818.

Reddiex AJ, Gosden TP, Bonduriansky R, Chenoweth SF. 2013. Sex-specific fitness consequences of nutrient intake and the evolvability of diet preferences. Am Nat 182: 91-102.

Reinhardt K. 2007. Evolutionary consequences of sperm cell aging. Q Rev Biol 82: 375-393.

Reznick DA, Bryant M, Holmes D. 2006. The evolution of senescence and post-reproductive lifespan in guppies (Poecilia reticulata). PLoS Biol 4: e7.

Richard M, Lecomte J, De Fraipont M, Clober J. 2005. Agespecific mating strategies and reproductive senescence. Mol Ecol 14: 3147-3155.

Rodríguez-Graña L, Calliari D, Tiselius P, Hansen BW, Sköld HN. 2010. Gender-specific ageing and non-Mendelian inheritance of oxidative damage in marine copepods. Mar Ecol Prog Ser 401: 1-13.

Roff DA. 1992. Evolution of life histories: Theory and analysis. Chapman \& Hall, New York.

Rowe L. 1994. The costs of mating and mate choice in water striders. Anim Behav 48: 1049-1056.

Sapienza P, Zaingales L, Maestripieri D. 2009. Gender differences in financial risk aversion and career choices are affected by testosterone. Proc Natl Acad Sci 106: 15268 15273.

Schroderus E, Jokinen I, Koivula M, Koskela E, Mappes T, Mills SC, Oksanen TA, Poikonen T. 2010. Intra- and intersexual trade-offs between testosterone and immune system: Implications for sexual and sexually antagonistic selection. Am Nat 176: E90-E97.

Stanton SJ, Liening SH, Schultheiss OC. 2011. Testosterone is positively associated with risk taking in the Iowa Gambling Task. Horm Behav 59: 252-256.

Stearns SC. 1992. The evolution of life histories. Oxford University Press, Oxford.

Stutt AD, Siva-Jothy MT. 2001. Traumatic insemination and sexual conflict in the bed bug Cimex lectularius. Proc Natl Acad Sci 98: 5683-5687.

Svensson E, Sheldon BC. 1998. The social context of life history evolution. Oikos 83: 466-477.

Tatarnic NJ, Cassis G, Siva-Jothy MT. 2014. Traumatic insemination in terrestrial arthropods. Ann Rev Entomol 59: $245-261$.

Torres R, Velando A. 2007. Male reproductive senescence: The price of immune-induced oxidative damage on sexual attractiveness in the blue-footed booby. J Anim Ecol 76: $1161-1168$.

van Doorn GS. 2009. Intralocus sexual conflict. Ann NY Acad Sci 1168: 52-71.

Velando A, Torres R, Alonso-Alvarez C. 2008. Avoiding bad genes: Oxidatively damaged DNA in germ line and mate choice. BioEssays 30: 1212-1219.

Vinogradov AE. 1998. Male reproductive strategy and decreased longevity. Acta Biotheoretica 46: 157-160.

Wigby S, Chapman T. 2005. Sex peptide causes mating costs in female Drosophila melanogaster. Curr Biol 15: 316321.

Williams GC. 1957. Pleiotropy, natural selection, and the evolution of senescence. Evolution 11: 398-411.

Williams GC. 1966. Natural selection, the costs of reproduction, and a refinement of Lack's Principle. Am Nat 100: 687-690. 
M.I. Adler and R. Bonduriansky

Zajitschek F, Hunt J, Zajitschek SRK, Jennions MD, Brooks R. 2007. No intra-locus sexual conflict over reproductive fitness or ageing in field crickets. PLoS ONE 2: e155.

Zajitschek F, Bonduriansky R, Zajitschek SRK, Brooks R. 2009a. Sexual dimorphism in life history: Age, survival, and reproduction in male and female field crickets Tele- ogryllus commodus under seminatural conditions. Am Nat 173: 792-802.

Zajitschek F, Brassil CE, Bonduriansky R, Brooks R. 2009b. Sex effects on life span and senescence in the wild when dates of birth and death are unknown. Ecology 90: 16981707. 


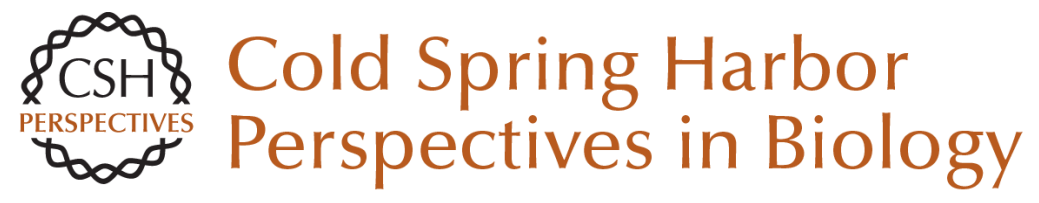

\section{Sexual Conflict, Life Span, and Aging}

Margo I. Adler and Russell Bonduriansky

Cold Spring Harb Perspect Biol 2014; doi: 10.1101/cshperspect.a017566 originally published online June 17,2014

\section{Subject Collection The Genetics and Biology of Sexual Conflict}

Mechanisms and Evidence of Genital Coevolution: The Roles of Natural Selection, Mate Choice, and Sexual Conflict

Patricia L.R. Brennan and Richard O. Prum

The Evolution of Sexually Antagonistic Phenotypes

Jennifer C. Perry and Locke Rowe

Reproductive Parasitism: Maternally Inherited

Symbionts in a Biparental World

Gregory D.D. Hurst and Crystal L. Frost

Sex-Biased Gene Expression and Sexual Conflict throughout Development

Fiona C. Ingleby, Ilona Flis and Edward H. Morrow

Human Homosexuality: A Paradigmatic Arena for

Sexually Antagonistic Selection?

Andrea Camperio Ciani, Umberto Battaglia and Giovanni Zanzotto

Sexual Conflict Arising from Extrapair Matings in Birds

Alexis S. Chaine, Robert Montgomerie and Bruce E. Lyon

Sexual Conflict and Seminal Fluid Proteins: A

Dynamic Landscape of Sexual Interactions

Laura K. Sirot, Alex Wong, Tracey Chapman, et al.

Conflict on the Sex Chromosomes: Cause, Effect, and Complexity

Judith E. Mank, David J. Hosken and Nina Wedell
Infanticide as Sexual Conflict: Coevolution of

Male Strategies and Female Counterstrategies Ryne A. Palombit

Copulatory Wounding and Traumatic Insemination

Klaus Reinhardt, Nils Anthes and Rolanda Lange

Sexual Conflict in Hermaphrodites

Lukas Schärer, Tim Janicke and Steven A. Ramm

Sexual Conflict and Sperm Competition

Dominic A. Edward, Paula Stockley and David J. Hosken

Sexually Antagonistic Zygotic Drive: A New Form of Genetic Conflict between the Sex

Chromosomes Urban Friberg and William R. Rice

Sex Chromosome Drive

Quentin Helleu, Pierre R. Gérard and Catherine Montchamp-Moreau

Is Sexual Conflict an "Engine of Speciation"? Sergey Gavrilets

Sexual Cannibalism as a Manifestation of Sexual Conflict

Jutta M. Schneider

For additional articles in this collection, see http://cshperspectives.cshlp.org/cgi/collection/

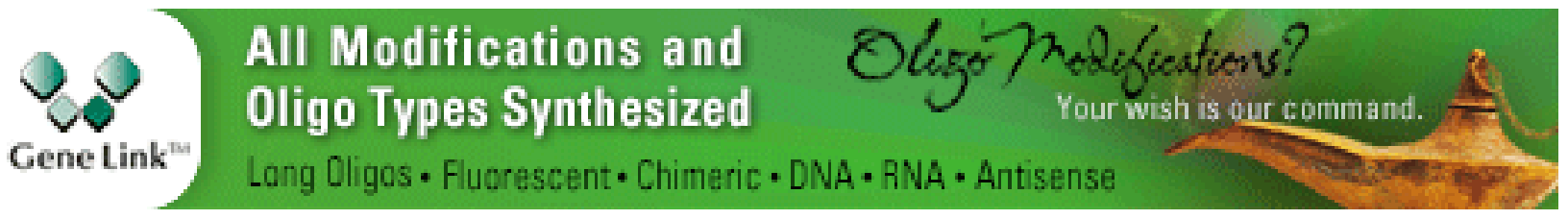


For additional articles in this collection, see http://cshperspectives.cshlp.org/cgi/collection/

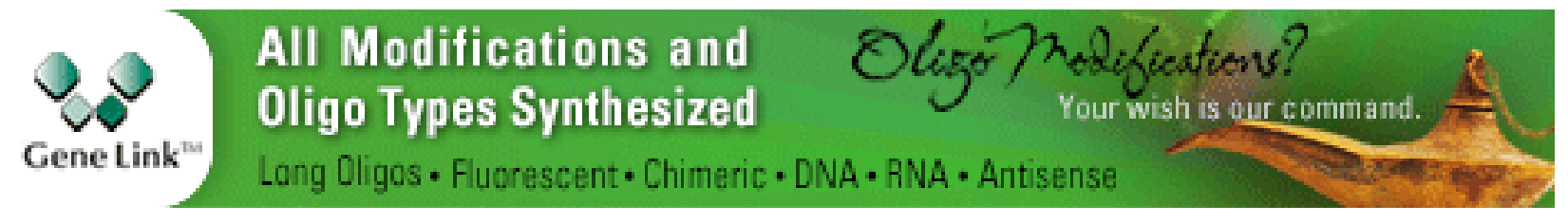

Copyright @ 2014 Cold Spring Harbor Laboratory Press; all rights reserved 